\title{
Iliac Fossa
}

National Cancer Institute

\section{Source}

National Cancer Institute. Iliac Fossa. NCI Thesaurus. Code C103454.

The large smooth and concave surface of the ilium. 